\title{
Fasciocutaneous cubital flap in soft tissue loss of the wrist
}

\author{
E Elena-Sorando MD, JL Arranz-López PhD, ML García-Martínez PhD, AA Núñez-Serrano PhD, \\ A De Juan-Huelves MD, P Benito-Duque PhD
}

E Elena-Sorando, JL Arranz-López, ML García-Martínez, AA Núñez-Serrano, A De Juan-Huelves, P Benito-Duque. Fasciocutaneous cubital flap in soft tissue loss of the wrist. Can J Plast Surg 2005;13(4):177-179.

Surgical managment of soft tissue loss in the wrist consists of suitable coverage for the protection of vascular, nervous and tendinous structures. The fasciocutaneous cubital flap covers wrist defects, providing safe support over the nerves, tendons and vessels. Reported here is five cases of wrist defects by different etiology (extravasations, autolysis, trauma and neuritis). A fasciocutaneous cubital flap successfully covered the soft tissue loss in all cases. This flap is applied in an easy, one-stage procedure and it maintains the major arteries of the forearm.

Key Words: Fasciocutaneous cubital flap; Soft tissue loss; Wrist

$\mathrm{M}$

anagement of soft tissue loss in the wrist is a challenging issue in hand surgery. Local flaps from the hand and forearm, microsurgical techniques and temporary pedicle flaps are options for the treatment of complex wrist defects $(1,2)$.

A fasciocutaneous cubital flap is a classic choice for covering areas of soft tissue loss in the distal third of the forearm, the wrist and the hand. In 1985, Becker and Gilbert (3), described this flap as a pedicled flap from the dorsal branch of the ulnar artery. We have not found many recent references about this flap, even though it has great local versatility.

The present paper reports five cases of soft tissue lesions in the wrist, which were repaired by a distally based fasciocutaneous cubital flap.

\section{Case 1}

\section{CASE PRESENTATIONS}

A four-year-old child presented with soft tissue loss over the volar carpal surface, exposing the median nerve, secondary to trauma in traffic accident (Figure 1). The flexor carpi radialis and palmaris longus (PL) were pulled off. A tendon graft of PL restored the flexor carpi radialis, and a fasciocutaneous cubital flap was used to cover the tendons with a sliding surface. Three weeks later, the child had total functional recovery (Figure 2).

\section{Case 2}

A 23-year-old woman suffered a cutaneous and tendinous (PL) loss on the right wrist after a traffic accident. The median nerve was intact. A fasciocutaneous cubital flap covered the defect over the flexor tendons, and also provided protection for

\section{Un lambeau cubital fasciocutané sur une perte de tissu mou du poignet}

La prise en charge chirurgicale de la perte de tissu mou du poignet consiste à couvrir assez la peau pour protéger les structures vasculaire, nerveuse et tendineuse. Le lambeau cubital fasciocutané couvre les anomalies du poignet et fournit un support sécuritaire au-dessus des nerfs, des tendons et des vaisseaux. Sont exposés cinq cas d'anomalies du poignet aux étiologies différentes (extravasations, autolyse, traumatisme et névrite). Dans tous les cas, un lambeau cubital fasciocutané permettait de couvrir la perte de tissu mou. L'avantage de ce lambeau est qu'il est appliqué dans le cadre d'une intervention simple en une étape et qu'il maintient les principales artères de l'avant-bras.

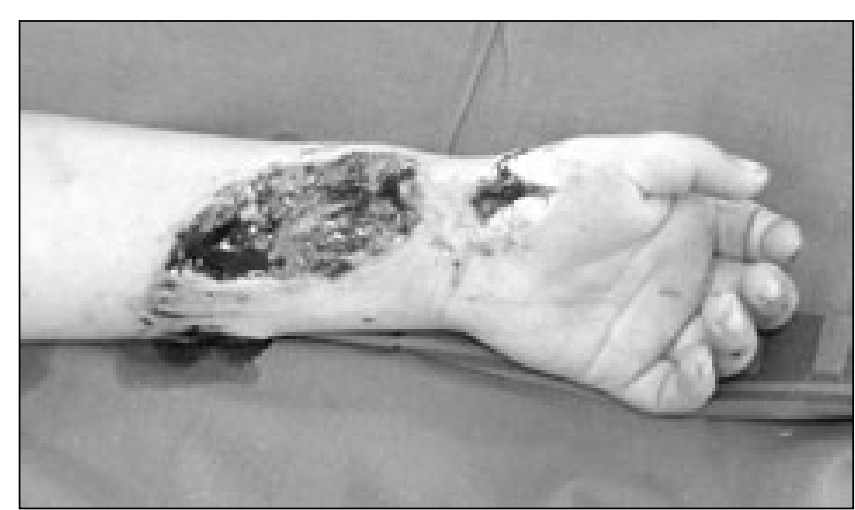

Figure 1) Soft tissue loss in wrist as a result of trauma sustained in a traffic accident

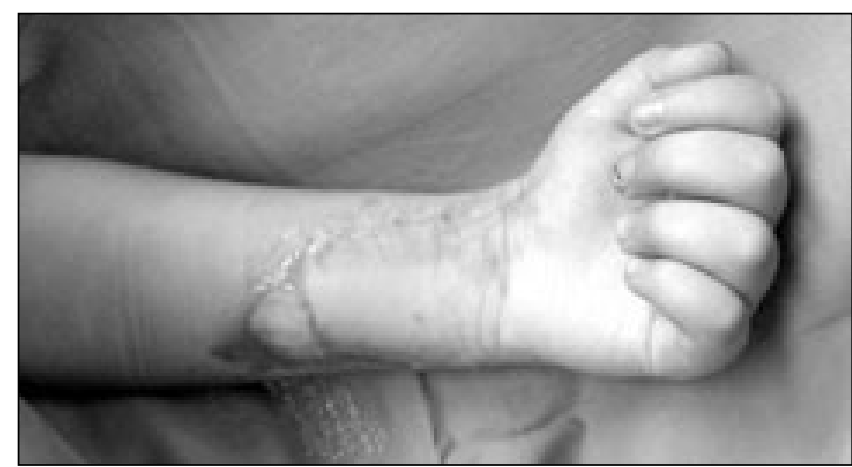

Figure 2) Aesthetic and functional outcomes 


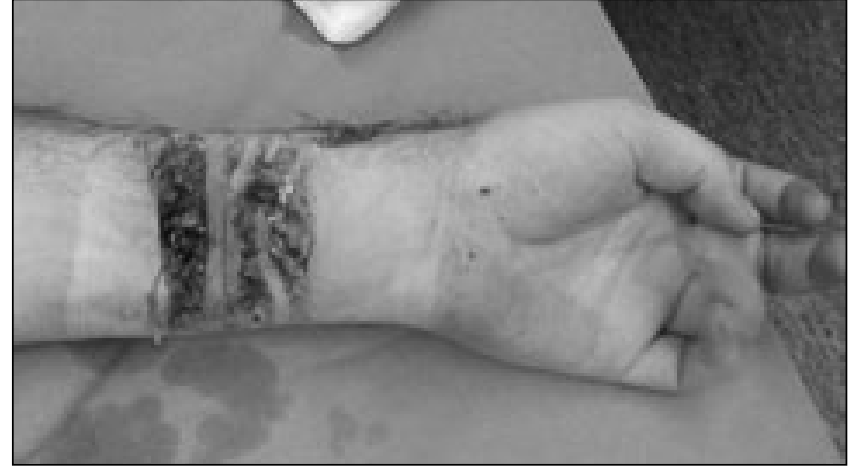

Figure 3) Traumatic self-inflicted injury, affecting the skin and several tendons

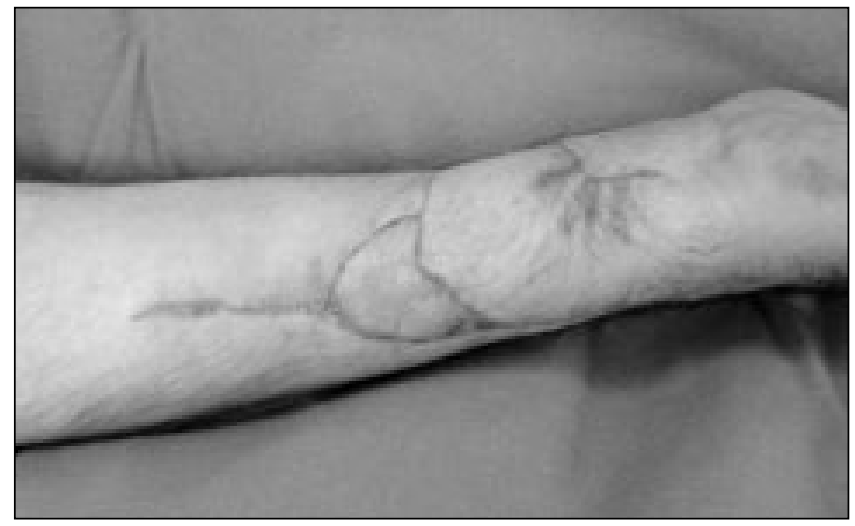

Figure 4) Clinical view, sixth week postoperatively

the median nerve. The functional recovery was perfect in three weeks.

\section{Case 3}

A 33-year-old man attempted suicide, which resulted in the severing of several flexor tendons and an associated cutaneous defect (Figure 3). The injury was repaired by tenorrhaphy of flexor digitorum superficiallis tendon in the second and fourth fingers, and the flexor digitorum profundus tendon of the third finger was also restored. The soft tissue defect was covered with a fasciocutaneous ulnar flap. The rehabilitation began early, and a follow-up six weeks later showed no functional limitation. The patient accepted the aesthetic outcome (Figure 4).

\section{Case 4}

A 54-year-old man with a history of non-Hodgkin's lymphoma presented with an extravasation injury located in the dorsum of the left hand as a result of his treatment with doxorubicin hydrochloride. After 14 days, extravasation of the cytotoxic agent resulted in a $5 \mathrm{~cm} \times 5 \mathrm{~cm}$ soft tissue defect involving the extensor digitorum tendons. The surgical repair consisted of debridement and a fasciocutaneous cubital flap to repair the defect, and a skin graft to cover the donor site. No complications were observed and the flexion and extension functions were entirely maintained.

\section{Case 5}

A 48-year-old carpenter presented with a large, painful scar on the wrist and palm of the left hand, that severely constricted the median nerve, a result of trauma from a circular saw. Using

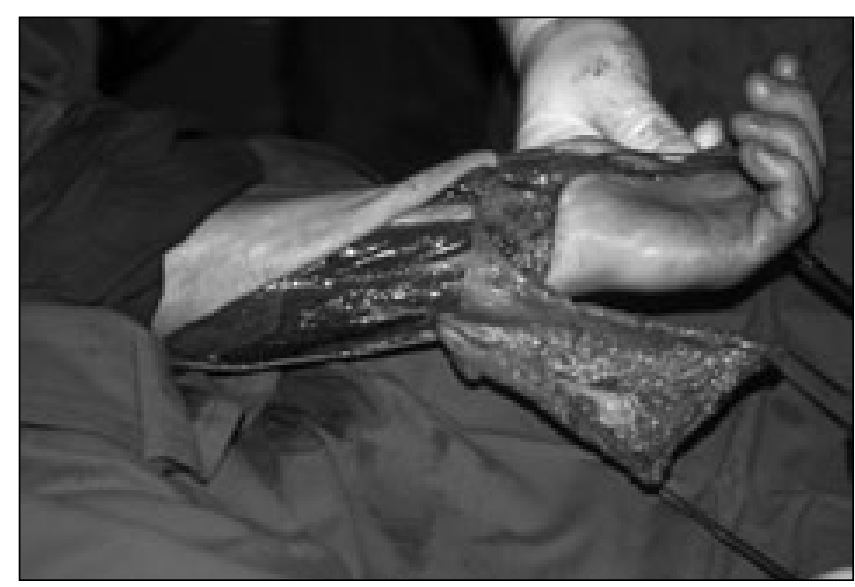

Figure 5) Adipofascial cubital flap, intraoperative view

an operating microscope, the authors performed an external neurolysis on the surrounding scar tissue, and an adipofascial cubital flap was detached (Figure 5). The fascial surface of this flap was used to cover the median nerve. A thin skin graft on the fascia restored the defect and the donor site was closed directly. The symptoms improved and the patient returned to work after two months, pain free.

\section{DISCUSSION}

The use of a forearm flap that is distally based on the radial or cubital arteries was rejected in these patients, because the perforator pedicled flaps allowed for coverage of soft tissue loss without sacrificing the axial arteries of the hand and forearm $(2,4)$.

The dorsal ulnar artery flap offers secure coverage of the tendons, nerves and vessels in the wrist, because it contains a sufficient amount of subcutaneous fat and underlying fascia of the flexor carpi ulnaris tendon. Vascular supply is via the ulnodorsal artery, which arises from the ulnar artery at a distance of $2 \mathrm{~cm}$ to $5 \mathrm{~cm}$ proximal to the pisiform (5).

The fasciocutaneous cubital flap presents a shorter pedicle and has a smaller degree of rotation than the posterior interosseous flap (6), but it offers many advantages: minimal donor site defect, no risk to the posterior interosseous nerve and easier execution than the posterior interosseous flap.

An alternative to this flap is the distally based perforator radial flap (preserving the radial artery), but it requires integrity of the vascular plexus in the deep fascia over the volar wrist and forearm, which are often injured in many traumas.

Free flaps are indicated for extensive defects, in which the tissue loss involves many structures with deep vascular damage. The patient with neuritis secondary to the formation of scar tissue (case 5) required the external neurolysis and the prevention of another scar adherence using the adipofascial flap to wrap the median nerve. The length and the quality of the fibrosis over the nerve influences the surgical reconstruction (7-9); severe and large constrictions should be repaired with a free flap such as a microvascular omental flap.

The surgical procedure was selected based on the location, size and special conditions of the complex defect of each patient. Before detachment of the flap, it was necessary to define the defect and determine the structures that needed coverage. Extravasation injuries require debridement of necrotic skin and the evaluation of the exposed structures (10). 


\section{CONCLUSIONS}

The fasciocutaneous cubital flap offers a safe wrist coverage; moreover, it is easily attainable and it leaves a minimal defect at the donor site.

The postoperative course is short and comfortable for the patients. Functional restoration is usually complete in all cases, and the secondary scars are minimal.

Although this flap has been replaced by free flaps for complex defects on the wrist, we recommend the cubital flap for its simple execution and effectiveness.

\section{REFERENCES}

1. Ceruso M, Angeloni R, Innocenti M, Lauri G, Capanna R, Bufalini C. [Reconstruction with free vascularized or island flaps of soft tissue loss in the upper limb after tumor resection. 16 cases.] Ann Chir Main Memb Super 1995;14:21-7.

2. Choupina M, Malheiro E, Guimaraes I, et al. Osteofasciocutaneous flap based on the dorsal ulnar artery. A new option for reconstruction of composite hand defects. Br J Plast Surg 2004;57:465-8.
3. Becker C, Gilbert A. Le lambeau cubital. Ann Chir Main 1988;7:136-42.

4. el-Khatib HA. Island fasciocutaneous flap based on the proximal perforators of the radial artery for resurfacing of burned cubital fossa. Plast Reconstr Surg 1997;100:919-25.

5. Masquelet AC, Gilbert A. An Atlas of Flaps of the Musculoskeletal System. London: Taylor \& Francis Group, 2003.

6. Goubier JN, Romana C, Masquelet AC. [The posterior interosseous flap in the child: 13 case reports.] Chir Main 2002;21:102-6.

7. Goitz RJ, Steichen JB. Microvascular omental transfer for the treatment of severe recurrent median neuritis of the wrist: A longterm follow-up. Plast Reconstr Surg 2005;115:163-71.

8. Voche P, Merle M. [The use of pedicular flap from the squared pronator muscle in the prevention and treatment of neuritis. Report of 8 cases.] Ann Chir Plast Esthet 1997;42:587-92.

9. Jones NF, Shaw WW, Katz RG, Angeles L. Circumferential wrapping of a flap around a scarred peripheral nerve for salvage of end-stage traction neuritis. J Hand Surg [Am] 1997;22:527-35.

10. Salameh Y, Shoufani A. Full-thickness skin necrosis after arginine extravasation - a case report and review of literature. J Pediatr Surg 2004;39:e9-11. 